\title{
Expert System Development Process of Integrated Disaster Management System for Lead Responding Agency in Malaysia During Response and Early Recovery Phases
}

\author{
Khairilmizal, S., M F Hussin, Ainul Husna, K., Ahmad Ihsan Mohd Yassin, Mohd Haikal Kasri and A \\ R Hussain
}

\begin{abstract}
The availability of experts during disaster response and recovery shall increase the capability and capacity of disaster management process. Challenges is that experts may not always be available all the time. Hence, an expert system such as Integrated Disaster Management System (IDMS) need to be developed in assisting emergency responders in managing disasters. Several models is available in developing an expert system, however it is found that each of this model is used to develop their own specific expert system causing it to be non-feasible for development of IDMS based on criteria of a computerized system for lead responding agency in Malaysia. Hence, it is the objective of this paper to outline the expert system development process of IDMS. Using document review and analysis method, four (4) past expert system development model were studied and analyzed. By comparing and understanding the four (4) past models, a seven (7) step expert system development process of IDMS is introduced which as the same time fulfilling the criteria of a computerized system for lead responding agency in Malaysia. It is the researcher's hope that the newly introduced Expert System Development Process will be utilized by other developers in future development of other expert system.
\end{abstract}

Keywords - expert system, disaster management, effective disaster management, entity relationship diagram.

\section{INTRODUCTION}

$\mathrm{D}$ ISASTER management is the process cycle of prevention, preparedness, response, and recovery. In ensuring the

This manuscript is submitted on $17^{\text {th }}$ October 2019 and accepted on $09^{\text {th }}$ March 2020. Khairilmizal Samsudin is with School of Health Science, USM (email: khairilmizal@usm.my)

Dr. Mohamad Fahmi Bin Hussin @ Mohamad is with Faculty of Electrical Engineering, UiTM (e-mail: fahmi478@salam.uitm.edu.my)

Ainul Husna Kamarudin is with UniKL, MESTECH (e-mail: ainulhusna@unikl.edu.my)

Ahmad Ihsan Mohd Yassin is with Faculty of Electrical Engineering, UiTM (e-mail: ihsan.yassin@gmail.com)

Mohd Haikal Kasri is with Fire and Rescue Department Malaysia (e-mail: Haikalkasripgb@gmail.com)

Abdul Razak Hussain is with PLC International Sdn. Bhd. (e-mail: razakerpics@gmail.com).

1985-5389/C 2021 The Authors. Published by UiTM Press. This is an open access article under the CC BY-NC-ND license (http://creativecommons.org/ licenses/by-nc-nd/4.0/). sustainability of the process cycle, the Malaysia National Security Council Directive 20 (MNSC 20) was introduced, which later updated to meet the requirement of the international framework in managing disasters in a country [1], [2].

MNSC 20 stated that a disaster management activity should be supported by technical agencies and experts [2]-[5]. There are needs for accurate decision making from experts to support responders during disasters response and recovery process [6], [7]. Unfortunately, experts may not be available all the time [5] hence, an expert system is needed as a solution in assisting emergency responders in managing disaster effectively [7], [8].

A review on disaster management towards lead responding agency summarized that disaster management in Malaysia especially during response and recovery phases, need to be supported by expert systems [4], [7], [9]. Advantages and challenges identified in several computerised disaster management systems were also discussed previously by researchers in previous publication on criteria for disaster management expert system in Malaysia [8]. It is summarized that that although each of the computerised systems identified to have its own advantage and strength in managing disasters, nearly all of the system have similar challenges which are either for a specific type of disaster or can only be used by the particular country it is designed for.

Hence, it is not advantageous to have an expert system that only is used for a specific type of disaster because there can be multiple disaster events at the same time [10][4]. The challenges here are to develop an expert systems for managing multiple disasters at the same time [8]. Hence, it should only be one (1) system needed and it is important for the lead responding agency in Malaysia to have IDMS [7], [11].

This paper is based on the system design and development of IDMS which consist of a database and an online system [10]. To properly develop the IDMS, there is a need to follow a solid process flow of expert system development [12], [13]. This process ensures that the system developed to meet the requirement of expert system and properly validated in ensuring the capability and capacity of the system is up to the expectations of the end-user [14], [15]. Hence, the focus of this paper is on the development process of IDMS, with the 
objective of introducing an improved process in developing an expert system.

Multiple process of developing expert system have been introduced by [6], [14]-[17]. However, including the challenges mentioned earlier, the uniqueness of Malaysia disaster management process [8], [18] will be an additional challenge in developing the IDMS. Therefore, the expert system development process of IDMS should also be able fulfill the criteria of a computerized system for lead responding agency in Malaysia [8] which the objective of this paper.

\section{Methodology}

Conceptualization of knowledge is a process of acquiring, organizing, and studying the knowledge regarding the problem identified earlier in order to develop a knowledge base [6]. This involves the process of collecting, eliciting, organizing, analyzing and interpreting the expert's system concepts to represent knowledge on [14] on the development process. In order to conceptualize the expert system development process, the document review and analysis method was used.

The process of document review and analysis method is to systematically understand and evaluate both printed and electronic materials [11], [19]. By using content analysis, the document review and analysis method includes finding, selecting, defining, and synthesizing data contained in documents and organized into major themes, categories, and case examples [20]. This gave the document analysis methods the capability to extract meaning, to gain understanding and to develop empirical knowledge from the examined and interpreted data [19].

Document analysis method has been used as a stand-alone method because it can serve a variety of purpose for research [10]. Among others, it includes information that suggests some questions or situation that need to observe as part of the research, information, and insights that can be valuable additions to a knowledge base, data, and information for research, means for tracking changes, and development, and validate findings or relate evidence from other sources [19].

Several articles and books were acquired and analyzed based on the keywords of an expert system or computerized system development. The authors come to a conclusion that In listing the IDMS development process, four (4) preceding models in developing an expert system from [14]-[17] shall be used.

The review made on all four (4) models has concluded that although they have some identical process in developing an expert system, some models shows different ways in developing an expert system. Following Table 1

Different development of the expert system as a basis for Design and Development of the Integrated Disaster Management System for FRDM summarise the process development of the expert system by the four (4) author [14][17].

TABLE 1

DIFFERENT DEVELOPMENT OF THE EXPERT SYSTEM AS A BASIS FOR DESIGN AND DEVELOPMENT OF THE INTEGRATED DiSASTER MANAGEMENT SYSTEM FOR FRDM

\begin{tabular}{lllll}
\hline & (Durkin, 1994) & (Rodriguez et. & (Winter, & (Sagheb, 2006) \\
& {$[16]$} & al., 2004) $[14]$ & 1998) $[17]$ & {$[15]$} \\
\hline 1 & Assessment & Identification & $\begin{array}{l}\text { Problem } \\
\text { modelling }\end{array}$ & $\begin{array}{l}\text { General } \\
\text { conception }\end{array}$
\end{tabular}

\begin{tabular}{lllll}
2 & Knowledge & $\begin{array}{l}\text { Conceptua- } \\
\text { lization }\end{array}$ & $\begin{array}{l}\text { Knowledge } \\
\text { representa- } \\
\text { tion }\end{array}$ & $\begin{array}{l}\text { Knowledge } \\
\text { conception }\end{array}$ \\
3 & - & - & $\begin{array}{l}\text { Knowledge } \\
\text { acquisition }\end{array}$ & - \\
4 & Design & Formalisation & $\begin{array}{l}\text { Inference } \\
\text { System } \\
\text { evaluation }\end{array}$ & Design \\
& Test & - & - & Implementation \\
6 & Implementation & Implementation & - & Improvement \\
7 & $\begin{array}{l}\text { Maintenance } \\
\text { and }\end{array}$ & Testing- & - & \\
& Development & & & \\
\hline
\end{tabular}

Durkin [16] stated that there are six (6) steps in developing an expert system starting from assessment; knowledge acquisition; design; test; implementation and; maintenance. Shaluf [6] based on Durkin model [16] developed his Technological Emergencies Expert System, which the process summarized as the following Fig. 1.

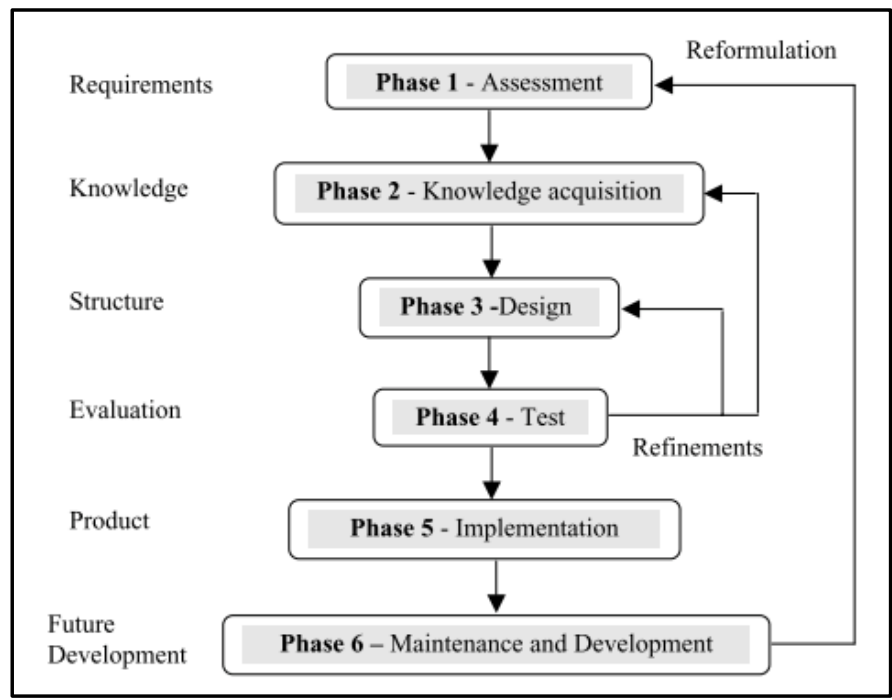

Fig. 1: Development phases of TEES [6] based on [16]

Assessment specifies the necessary features and scope of the system [16] where the problem feasibility and justifications for the system which defined the overall goals [6]. Knowledge acquisition is a process of acquiring, organizing, and studying knowledge that is collected [16] which will guide the development efforts. Shaluf [6] stated that knowledge acquisition includes the qualitative and quantitative knowledge that needed to be extracted, organized and translated into a form of rules to build the system. While quantitative knowledge can be drawn from the field survey, qualitative knowledge is obtained from the literature and domain experts [19], [21].

Next step stated by Durkin [16] is designing the expert system. During this step, a software tool can be used the overall structure of the system is defined and to represent the knowledge acquired in a manner similar to the approach taken by the human expert [6]. The testing phase is a continual process throughout the development phase of an expert system [16]. Using validity method as utilized by [22], the aim of the testing is to validate the overall structure of the system and its knowledge in determining whether the right system was built, and does what it was meant to do at an acceptable level of accuracy. The next and final steps stated by [16], [23] is the implementation and the maintenance and development of the 
expert system. The target group implements the developed expert system and at the same time, maintenance and software update is made in order to meet current needs after the implementation process [6], [16], [24].

Rodriguez [14] on the other hand, stated that there are five (5) steps in developing an expert system starting with identification; conceptualization; formulization; implementation and finally; testing. Although [14] stated that the process is a general expert system design, elaboration is made at each process steps where identification is a process of identifying problem characteristics. Conceptualization, on the other hand, is finding concepts to represent knowledge, followed by formalization, which is designing the structure to organize knowledge, the implementation for formulating rules to embody knowledge and finally, testing is validating rules that organize knowledge. Significance difference found in [14] steps is that testing is made after implementation which differs from the process introduced by [15]-[17] in developing an expert system. Furthermore, Rodriguez [14] did not have any maintenance process of an expert system as in [15], [16].

Winter [17] also introduced five (5) steps in developing an expert system, but have a significant difference compared to steps by [14]-[16] where there are no implementation and maintenance. These process include problem modelling, which is identifying the requirement of expert system; knowledge representation which is formalising decision tree for the expert system; inference which is the process of designing the expert system and finally; system evaluation which is the process of testing the expert system to meet the requirement of end-user [17]. Comparing to other authors, Winter [17] introduced a knowledge acquisition process which is the decision-making process and the database system for the development of an expert system.

Finally, past expert system development process studied in developing an expert system for this research is by [15]. Using also a five (5) steps process in developing an expert system, [15] stated that the process involves general conceptualization; knowledge conception and design same as [14], [16], [17]. Skipping the process of testing the expert system [16], [17], [15] proceeded with the process of implementation and improvement of the expert system which is similar to [14], [16]. In the process introduced by [15], the process of general conceptualization and knowledge conception were given priority as it is stated that $80 \%$ of obstacles in expert system development is knowledge acquisition.

The process of development of expert system introduced by [14]-[17] is the basis for the development of the expert system for this research which will be elaborated in result and discussions.

\section{RESULT AND DISCUSSION}

Based on the methodology presented earlier, the expert system development process for the IDMS is as outlined in Table 2 and supported by process flow in Fig. 2. This results comes from the process of understanding and analysing of the previous expert system design and development process introduced by [14]-[17] as indicated in Table 1
TABLE 2

DEVELOPMENT PROCESS OF IDMS

\begin{tabular}{|c|c|}
\hline IDMS & Description \\
\hline Structuring problem & $\begin{array}{l}\text { Process of identifying and structuring the } \\
\text { problems and issues faced by the end-user }\end{array}$ \\
\hline $\begin{array}{l}\text { Conceptualization of } \\
\text { knowledge }\end{array}$ & $\begin{array}{l}\text { Process of obtaining pertinent and important } \\
\text { information from end-user so that a systemize } \\
\text { solution can be designed and developed }\end{array}$ \\
\hline Database design & $\begin{array}{l}\text { Process of designing and developing the database } \\
\text { for the systemize solution identified }\end{array}$ \\
\hline System design & $\begin{array}{l}\text { Process of developing the system and linking it } \\
\text { with the developed database }\end{array}$ \\
\hline Compliance test & $\begin{array}{l}\text { The evaluation made by end-user to verify the } \\
\text { usability, accessibility, and experience of using } \\
\text { the developed system }\end{array}$ \\
\hline Implement & Implementation of the system by end-user \\
\hline $\begin{array}{l}\text { Sustainability and } \\
\text { improvement }\end{array}$ & $\begin{array}{l}\text { Process of sustaining and improving the system } \\
\text { as needed either by end-user or developer }\end{array}$ \\
\hline
\end{tabular}

There are seven (7) steps in the development of IDMS. The seven (7) steps which shall be discussed in the sequence include structuring problem; conceptualization of knowledge; database design; system design; compliance test; implementation and finally, and; sustainability and improvement.

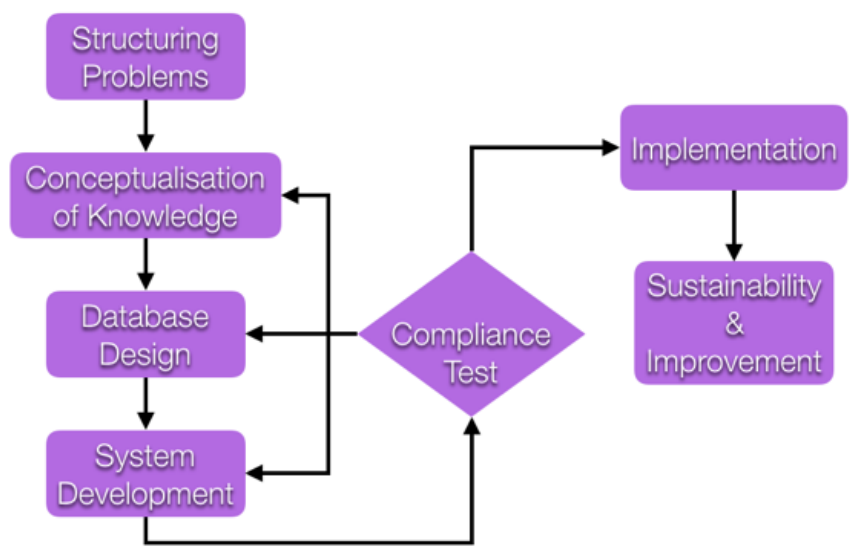

Fig. 2: Process flow development of Integrated Disaster Management System (IDMS)

\section{A. Structuring Problem}

The first expert system development process for IDMS is to identify and structure the problems as mentioned by [6], [14], [15], [17]. This conception can be based upon concepts such as philosophy, intelligence, ethics and politics [15]. This process focuses on the problem feasibility (the need of system and experts in managing disaster) and justifications (insufficient of experts in managing disaster and all information are manually recorded) in developing the overall purpose, feature, and scope [6] of IDMS. The purpose of this process is to identify the issues that will develop the overall structure and resource needed for IDMS study [17]. The problem(s) are then characterized in order to develop the overall concept [25].

\section{B. Conceptualization of Knowledge}

The second expert system development process for IDMS is the conceptualization of knowledge as stated by [6], [14], [15], [17]. Conceptualization of knowledge is the process of 
acquiring, organizing, and studying the knowledge of the problem identified earlier in order to develop a knowledge base [6]. Conceptualization of knowledge involves the process of collecting, eliciting, organizing, analyzing and interpreting the disaster management concepts to represent knowledge [14] of the current understanding of disaster management environment.

Both structuring problem and conceptualization of knowledge for IDMS requires a systematic reviewing method of documents which include both printed and electronic materials. Hence, document analysis methods gave the capacity to extract meaningful understanding so as to develop empirical knowledge from the data that is examined and interpreted [19]. Document analysis method has been used to systematically review and evaluate both printed and electronic materials for IDMS development [19]. Document analysis method also has been widely used in three (3) ways where first is to identify a research problem, specifying a purpose of research, research question or hypotheses; secondly, is for reviewing the literature, reporting and evaluating research; and finally for collecting, analysing and interpreting qualitative or quantitative data [19], [20].

In terms of methods of achieving the objective of developing IDMS, it is believed that the strengths of document analysis are considerably higher rather than other types of methods such as observations or questionnaire [19]. The reason is that the document analysis method is a low-cost way of obtaining empirical data which are appropriate to the gap identified earlier and towards the study's conceptual framework [19]. Hence, document analysis method seems more advantageous due to its efficiency comparing to other methods in terms of availability of documents, cost-effective, the stability of the information provided and most importantly, the document can be accessed for a long span of time [19]. Study also shows that document analysis method has been used as a stand-alone method because it can serve a variety of purpose for research [19]. The variety of purpose stated by [19] in using document analysis method includes:

1. Data and information for research;

2. Information and insights that can be valuable additions to a knowledge base;

3. Information that suggests some questions or situation that need to observe as part of the research;

4. Means for tracking change and development;

5. Validate findings or relate evidence from other sources.

The document analysis variety of purpose itself has proven the that the methods research capability. The use of document review method is also supported by [20] which emphasizes that document analysis method includes finding, selecting, defining, and synthesizing data contained in documents and organized into major themes, categories, and case examples specifically through content analysis.

There are some constraints for document analysis method, such as the possibility of the document have insufficient details due to the purpose of the document is not for research including regulations and government documents [19]. However, for the development of IDMS, these limitations can be neglected as the document identified comes from a wide range of types which also include articles, books, and formal education and training materials [10]. Although there are some government documents used, it was found that in terms of disaster management, these documents are based on international understanding [2], [18]. Other limitations stated by [19] such as low retrievability and biased selectivity are also negligible because documentation on disaster management are widely accessible through countless sources and due to the context of this paper, biased selectivity disadvantages is non-existent. Even [19] agree that the limitation is only potential flaws considering that document analysis offers advantages that clearly outweigh the limitations.

The data acquired during the conceptualization of knowledge process are validated systematically. Validity is an important process in order to measures a research's success at what the researcher sets out to do, as it refers to the degree in the research tool that is truly measuring what it is intended to measure [22]. While content validity is a validation of instruments based on credible resources, face validity is a test that 'appears' as if it is going to measure what it is supposed to measure, and at the same time affirmed by the researcher or domain experts [22]. For the purpose of this research, selection of domain experts have also been mention by several researchers which include tacit and explicit knowledge on their field [26], [27]. With both validity method, the accuracy of data collected, and conclusion derived can be considered as solid. Conceptualization of knowledge process was able to provide the overall view of developing IDMS including formalizing the knowledge base [15], [17].

\section{Database Design and Development}

Based on the second process of conceptualization of knowledge, the next process for the expert system development process for IDMS database is the design and development of the database as suggested by [17], [28]. This process involves developing a model of information chain and processing of logic from the acquired knowledge [17]. For the IDMS database designing purpose, Entity Relationship Diagram (ERD) which is a subset of a semantic model in database design where it is best-known tools for logical database design [28] is used. The reason for using ERD for this research is because of the capacity of it to be understood by non-specialists; easily conceptualised where it provides a simple way of representing a user's information requirements and finally; it is a model that describes the world in terms of entities and attributes that is most suitable for computer-naïve end users [28].

IDMS database will be developed based on Structured Query Language (SQL) and using XAMPP which is a popular readyconfigured all-in-one package for developing and testing database due to the graphic user interface capability [13]. The Design and Development of IDMS-Database are already discussed and published in [10], hence no further detailed discussion shall be made in this paper.

\section{System Development}

The next process of the expert system development process for IDMS is the system development as outlined by [6], [14], [15], [17]. System development is where the knowledge base 
gathered during the conceptualization of knowledge and the database designed using the ERD will be formulated into the system [14]. It is important that in the system development process, the inference which comprises the conceptualization of knowledge and database design capable of providing adequate interaction between the end-user [17].

A web-based system, has been used previously for facilitating disaster management where a web-based system allows for faster data retrieval when it is needed in order to make appropriate decisions [8], [29]. The IDMS is proposed to be a web-based system that will be developed using Hyper Text Mark-up Language (HTML) editors. HTML is the basic building block of a web page. Having a graphical user interface (GUI) implemented using HTML which will provide the enduser with the simplicity of usage [12]. HTML also are capable of providing interactive information interchange between a user server and web pages especially in having a database [30].

The concept of the IDMS is as illustrated in Fig. 3 Fire and Rescue Department Malaysia (FRDM) as one of the lead responding agency during disasters and the forward incident commander at the On-Scene Command Post [3], [31]. FRDM is the center for information on command structure, logistic and resources incident information and supportive information. With assistance from IDMS, this information's will be easily recorded and managed.

1. Command Structure: information includes the person-incharge of the overall operations and the smaller incident within each operation. The command structure is based on Malaysia disaster management policy Chain of Command [3], [32];

2. Logistic and resources: information includes logistical units involved in the operations which include its origin and status of the units;

3. Incident information: information includes, situation awareness, incidents log, victim's information's and hazards information's;

4. Supportive information: information's include meteorological information's, incident location information and area mapping.

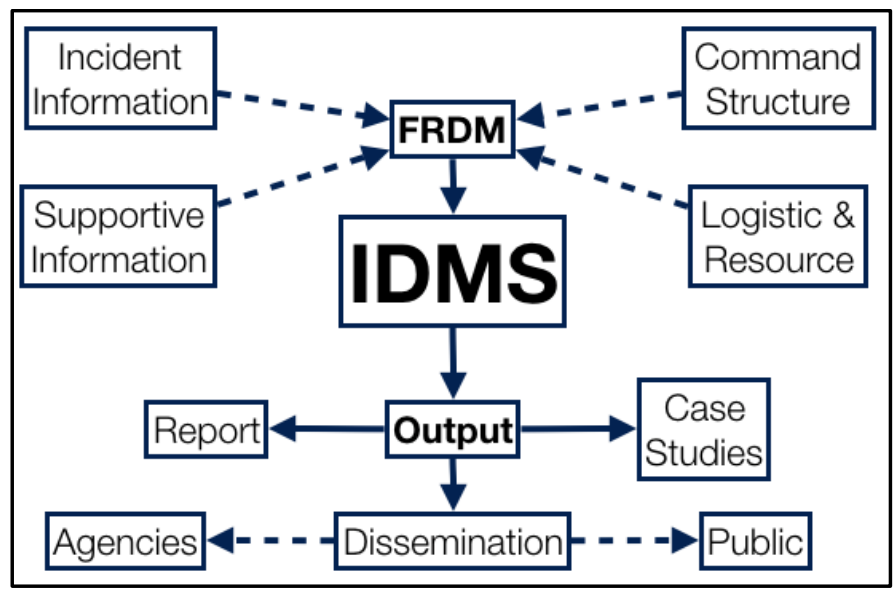

Fig. 3: Integrated Disaster Management System Concept

IDMS will manage all this information's so that it can produce the required output to the targeted recipient. IDMS at the same time complement the criteria for an integrated disaster management system in Malaysia as outlined by [8] through the process of:

1. Dissemination of critical information to other involved agencies on-site to assure up-to-date information's among agencies;

2. Dissemination of needed information to the public including media;

3. Information for the purpose of preliminary reporting, current situation reporting (SitRep), and final reporting;

4. Information for the purpose of training, research and investigations.

\section{E. Compliance Test}

The compliance test is the next process of the expert system development process for IDMS after system development process as suggested by [6], [17]. The compliance test is where the end-user will look at the overall usage of IDMS. This test is an assessment procedure which examines the overall problem structuring, conceptualization of knowledge and database design of the system [17]. The end-user or the domain expert itself will be doing the compliance test to assure that the system is satisfactory and accepted [6].

Compliance test process involved the process of validating the IDMS. A structured questionnaire were given to the domain experts in measuring capability of IDMS [22]. The questionnaire listed the important system features that were identified during the conceptualization of knowledge process, and evaluate the acceptance of respondents towards IDMS through the given features [6].

The system was evaluated through a structured questionnaire adopted from [33] containing views on the developed system towards domain experts namely safety professionals and lead responding agency officers.

TABLE 3

DOMAIN EXPERTS FACE VALIDITY FOR IDMS

\begin{tabular}{lcc}
\hline & Mean & $\begin{array}{c}\text { Standard } \\
\text { Deviation }\end{array}$ \\
\hline IDMS information quality & 4.33 & 0.16 \\
IDMS usefulness & 4.28 & 0.25 \\
IDMS usage characteristic & 4.44 & 0.27 \\
Overall satisfaction & 4.25 & 0.52 \\
\hline
\end{tabular}

Analysis of the collected data as shown in Table 3 indicates that domain experts are satisfied with the IDMS system. Mean score for quality of information in IDMS is 4.33 with a standard deviation of 0.16. IDMS are also acceptably useful with a mean score of 4.28 and standard deviation of 0.25 . In terms of usage characteristic, the acceptance of IDMS is 4.44 with a standard deviation of 0.27 . Overall, IDMS proved to be satisfactory by domain experts where mean score is 4.25 and standard deviation of 0.521 . This validation process indicates that the IDMS are ready to be used by the lead responding agency in Malaysia. 


\section{F. Implementation}

After the compliance test, the next process of expert system development process for IDMS is implementation process where it will be implemented by the end-user as stated by [6], [14], [15]. The end-user for IDMS is the FRDM. The implementation process is the process where the end-user interacts with the system and use the system as it is designed for [6]. It is a process where the conceptualization of knowledge was presented as a system for the end-user [14] and the success is based on the database design and the system development process [15]. However implementation of system is not within the control of researchers as the decision is made by end-user which is part of the limitation for IDMS [10].

\section{G. Sustainability and Improvement}

The Final process for expert system development process for IDMS is sustainability and improvement as stated by [6], [14], [15]. Sustainability and improvement come after the implementation process and a final process in any system development [15]. Sustainability and improvement come from the advancement of knowledge or even the identification of new problem which may need to change how the developed system work and conducted by a competence person [6]. This process involved reviewing back the conceptualization of knowledge, the database design process and the development of the system itself [14].

\section{CONCLUSION}

IDMS has the capability to assist responders in managing emergency especially during response and early recovery phase. In ensuring the capacity and capability of IDMS, the system should be developed based on a concrete expert system development process. The seven (7) steps of expert system development process presented earlier indicates that the design and development of IDMS shall be able to meet the end-user needs and at the same time fulfill the criteria for a disaster management system for lead responding agency in Malaysia [8]. With the outlined experts system development process, the design and development of IDMS can be more systematic, and most importantly meets the end-user requirements. It is the researcher's aspiration that the expert system development process can be utilized for other type of expert system design and development.

\section{REFERENCES}

S. Khairilmizal et al., "Evolution of Disaster and Disaster Management Policy in Malaysia," Adv. Sci. Lett., vol. 22, no. 12, pp. 4209-4212, Dec. 2016.

[2] S. Khairilmizal, M. F. F. Hussin, K. Ainul Husna, A. R. R. Hussain, M. H. Jusoh, and A. A. Sulaiman, "Implementation of Disaster Management Policy in Malaysia and its Compliance Towards International Disaster Management Framework,” Int. J. Inf., vol. 19, no. 8A, 2016.

[3] MNSC, Policy and Mechanism of Disaster in Malaysia. Malaysia: Malaysia National Security Council, Prime Minister Department, 2012, p. 44.

[4] S. Khairilmizal et al., "Model of an Incident Potential Index and Integrated Disaster Management Online System for Lead Responding Agency in Malaysia During Response and Recovery Phase," in
Technology and Applications for Disaster Management 2nd International Conference, 2016.

[5] M. F. Hussin et al., "The Role of Human Factors in Emergency Management: A Malaysian Company Perspective," Int. J. Eng. Technol., vol. 7, no. 3, pp. 490-493, 2018.

[6] I. M. Shaluf and F.-R. Ahmadun, "Technological emergencies expert system (TEES)," Disaster Prev. Manag., vol. 15, no. 3, pp. 414-424, 2006.

[7] S. Khairilmizal et al., "The Need for an Integrated Disaster Management System for Lead Responding Agency in Malaysia During Response and Recovery Phase," Int. J. Inf., vol. 19, no. 8A, pp. 3307-3311, 2016.

[8] S. Khairilmizal et al., "Criteria for an Integrated Disaster Management System for Lead Responding Agency in Malaysia," Adv. Sci. Lett., vol. 23, no. 5, pp. 4278-4280, May 2017.

[9] K. Ainul Husna, B. Siti Hawa, M. F. Hussin, and S. Khairilmizal, "Effective Emergency Management : A Malaysian Public Listed Oil and Gas Company Perspective," in International Medical Science Technology Conference (IMSTC2016), 2016.

[10] S. Khairilmizal et al., "Design and Development of Strategic Disaster Management Database for Lead Responding Agency in Malaysia during Response and Early Recovery Phases," Int. J. Electr. Electron. Syst. Res., vol. 10, 2017.

[11] W. A. H. Wan Ahmad Syafiq, M. F. Hussin, S. Khairilmizal, A. I. M. Yassin, and A. M. Rafi, "Disaster Management System Based on Lavenberg-Marquardt Algorithm Artificial Neural Network," Int. J. Electr. Electron. Syst. Res., vol. 11, 2017.

[12] S. Kumar and R. B. Mishra, "Web-based expert systems and services," Knowl. Eng. Rev., vol. 25, no. 02, pp. 167-198, Jun. 2010.

[13] A. W. West, Practical PHP and MySQL Website Databases: A Simplified Approach (Expert's Voice in Web Development), 1st ed., vol. XXXIII, no. 2. Apress, 2013.

[14] A. Rodriguez-Bachiller and J. Glasson, Expert systems and geographical information systems for impact assessment. New York, NY: Taylor \& Francis, 2004.

[15] M. Sagheb-Tehrani, "The design process of expert systems development: some concerns," Expert Syst., vol. 23, no. 2, pp. 116125, May 2006

[16] J. Durkin, Expert Systems: Design and Development, 1st ed. London: Macmillan Coll Div, 1994

[17] S. J. Winter, "Methodology development of an engineering design expert system utilizing a modular knowledge-base inference process," Iowa State University, 1998.

[18] S. Khairilmizal et al., "Policy on Disaster Management in Malaysia: The Need of Supporting Governance," Adv. Sci. Lett., vol. 22, no. 12, pp. 4213-4215, Dec. 2016.

[19] G. A. Bowen, "Document Analysis as a Qualitative Research Method," Qual. Res. J., vol. 9, no. 2, p. 19, 2009.

[20] A. Labuschagne, "Qualitative research: Airy fairy or fundamental?," Qual. Rep., vol. 8, no. 1, 2003.

[21] J. Corbin and Anselm L. Strauss, Basics of Qualitative Research: Techniques and Procedures for Developing Grounded Theory, 3rd ed. Los Angeles, Calif.: SAGE Publications, 2008.

[22] M. F. Hussin, B. Wang, and R. Hipnie, "The reliability and validity of Basic Offshore Safety and Emergency Training knowledge test," J. King Saud Univ. - Eng. Sci., vol. 24, no. 2, pp. 95-105, 2012.

[23] J. P. Li, R. Chen, J. Lee, and H. R. Rao, "A case study of privatepublic collaboration for humanitarian free and open source disaster management software deployment," Decis. Support Syst., vol. 55, no. 1, pp. 1-11, Apr. 2013.

[24] A. Mansourian and A. Rajabifard, "Using SDI and web-based system to facilitate disaster management," Comput. Geosci., vol. 32, no. 3, 2006.

[25] I. Becerra-Fernandez, G. Madey, M. Prietula, D. Rodriguez, R. Valerdi, and T. Wright, "Design and development of a virtual Emergency Operations Center for disaster management research, training, and discovery," in Proceedings of the Annual Hawaii International Conference on System Sciences, 2008.

[26] Z. Pourzolfaghar, R. Ibrahim, R. Abdullah, and N. M. Adam, "A Technique to Capture Multi-Disciplinary Tacit Knowledge During the Conceptual Design Phase of a Building Project," J. Inf. Knowl. Manag., vol. 13, no. 02, Jun. 2014.

[27] Z. Pourzolfaghar, R. Ibrahim, R. Abdullah, and N. M. Adam, Potential technique for capturing building design tacit knowledge to decrease cost and time overruns. Caen, France: Academic 
Publishing, Normandy Business School, 2011.

[28] S. Bagui and R. Earp, Database Design Using Entity-Relationship Diagrams, 2nd ed. Boca Raton, FL: CRC Press, 2003.

[29] N. Katuk, K. R. Ku-Mahamud, N. Norwawi, and S. Deris, "Webbased support system for flood response operation in Malaysia," Disaster Prev. Manag., vol. 18, no. 3, pp. 327-337, 2009.

[30] P. Wangphanich, "A simple web-based expert system for a supplier assessment: A case of a JIT production environments," in Proceedings 2011 International Conference on System Science and Engineering, ICSSE 2011, 2011, pp. 96-100.

[31] JBPM, Arahan Pelaksanaan Tugasan Komander Operasi, 3rd ed. Putrajaya: JBPM Putrajaya, 2014.

[32] FRDM, "Incident Management System," in Procedure in applying Certificate of Completion and Compliance, Putrajaya, Malaysia: Fire Safety Division, Fire and Rescue Department, 2008.

[33] B. Armstrong, G. Fogarty, D. Dingsdag, and J. Dimbleby, "Validation of a Computer User Satisfaction Questionnaire to Measure IS Success in Small Business," J. Res. Pract. Inf. Technol., vol. 37 , no. 1, pp. 27-42, 2005. 